\title{
MEMASUKI MASA USIA MENOPAUSE DITINJAU DARI USIA MENARCHE DAN JUMLAH ANAK
}

\author{
Winarni ${ }^{1, *}$, Dyaswati $\mathbf{R}^{2}$ \\ ${ }^{1,2}$ Universitas Aisyiyah Surakarta \\ ${ }^{1}$ bunda.aya06@gmail.com*
}

\begin{abstract}
Abstrak
Latar Belakang: Usia Harapan hidup semakin panjang, sehingga populasi wanita menopause semakin meningkat. Bervariasinya usia memasuki menopause disebabkan berbagai faktor yang mempengaruhinya.. Beberapa faktor tersebut antara lain usia pertama kali menstruasi, stress, pemakaian metode kontrasepsi, status perkawinan, jumlah anak dan usia melahirkan anak terakhir, pekerjaan, pendapatan, merokok, dan minum alkohol.

Tujuan: Penelitian ini bertujuan untuk mengetahui apakah usia menarche dan jumlah anak berhubungan dengan usia menopause

Metode: Penelitian menggunakan metode observasi analitik dengan pendekatan retrospektif. Populasi penelitian adalah ibu yang sudah menopause di Kelurahan Karangjati, Wonosegoro, Boyolali. Jumlah sampel sebanyak 82 ibu menopause. Teknik pengambilan sampel menggunakan simple random sampling. Instrumen penelitian menggunakan lembar observasi diisi dengan wawancara. Analisa data menggunakan korelasi pearson, dengan taraf signifikansi $95 \%$.

Hasil: Usia menarche dengan rata-rata usia 13 sebagian besar usia menarche 14 tahun yaitu sebanyak $(34,1 \%)$.Jumlah anak rata rata 3,90, sebagian besar ibu mempunyai anak 4 orang $(30,4 \%)$. Usia menopause dengan rata-rata usia 49,63 sebagian besar ibu dengan usia menopause 50 tahun yaitu sebanyak $(36,6 \%)$. Hasil uji korelasi Pearson antara usia menarce dan usia menopause nilai koefisien korelasi sebesar negaif (-) 0,580 dan p value $(<0,001)$. Sedang uji korelasi Pearson dengan antara jumlah anak dan usia menopause nilai koefisien korelasi sebesar 0,148 dan $p$ value $(0,185)$.
\end{abstract}

Simpulan: Ada hubungan signifikan antara usia menarche dengan usia menopause pada ibu menopause, sedangkan jumlah anak tidak berhubungan dengan usia menopause pada ibu menopause di Kelurahan Karangjati, Wonosegoro, Boyolali.

Kata Kunci : menopause; usia menarche; jumlah anak

\section{ENTERING MENOPAUSE AGE REVIEWED FROM MENARCHE AGE AND NUMBER OF CHILDREN}

\begin{abstract}
Background: With the increasing length of life expectancy, the population of women's menopause is growing.Variations in the menopause age caused by various factors that influence it. Several factors, they are age at first menstruation, stress, use of contraceptive methods, marital status, numbers of
\end{abstract}


children and the last age of child-bearing, family history, occupation, income, smoking, and drinking alcohol.

Purpose: The research is to know that is the menarche age and number of children correlate to menopause age or not, on menopausal women in Karangjati Village Wonosegoro, Boyolali.

Method: This research used observational analytic study with retrospective approach. The research population was women who had menopause at Karangjati Village Wonosegoro Boyolali. The total sample was 82 mothers who had menopause. The sampling technique used simple random sampling. The research instruments used the observation sheet filled with interviews. The data analysis used Pearson correlation with 95\% of significance level.

Result: The average of menarche age is 13, most of them are the menarche age of 14 years old as many (34.1\%). The average of number of children is 3,90 most of them are the mothers who have 4 children (30,4\%). The menopause age with the average age of 49.63 mostly women with menopausal age of 50 years old as many (36.6\%). The first. results of Pearson correlation test are that between menarche age and menopause age is negative (-)0.580 of coefficient correlation number and $(<0.001)$ of $p$ value. The second results of Pearson correlation test are that the number of children and menopause age is about 49,63 of coefficient correlation number and (0.185) of $p$ value.

Conclusion: There is a significant correlation between menarche age with menopause age on menopausal women, And besides that, the number of children is not correlate to menopause age on menopausal women in Karangjati Village, Wonosegoro, Boyolali.

Key Word: menopause age; number of children; menarche

\section{PENDAHULUAN}

Angka harapan hidup merupakan salah satu indikator penting dalam menentukan tingkat kesehatan masyarakat. Badan Kesehatan Dunia, World Health Organization (WHO) memperkirakan usia harapan hidup orang Indonesia adalah 75 tahun pada tahun 2025. Hal ini berarti perempuan memiliki kesempatan untuk hidup rata-rata 25 tahun lagi sejak awal menopause.

Menjadi tua adalah suatu proses yang merupakan bagian dari kehidupan seseorang, dan sudah terjadi sejak konsepsi dalam kandungan yang berlangsung terus sepanjang kehidupan. Usia lanjut mengandung pengertian adanya perubahan yang progresif pada organisme yang telah mencapai kemasakan, perubahan ini bersifat umum dan irreversible (tidak dapat kembali). Di dalam siklus terakhir, wanita akan mengalami masa kesuburannya berakhir (menopause). Menopause merupakan masa berakhirnya siklus menstruasi yang terdiagnosis setelah 12 bulan tanpa periode menstruasi. Terjadinya menopause pada wanita, diikuti berbagai gejolak meliputi aspek fisik maupun psikologis yang dapat mempengaruhi berbagai aspek kehidupan dari wanita tersebut. Masuknya seorang dalam fase menopause berbeda-beda. Apabila diambil rata-rata, seorang wanita mengalami menopause sekitar usia 45-50 tahun (Kusmiran, 2011; Lestary, 2010; Kumalasari dan Andhyantoro, 2012). 
Bervariasinya usia memasuki menopause disebabkan berbagai faktor yang mempengaruhinya. Salah satu faktor tersebut adalah usia saat menstruasi pertama kali atau disebut juga menarche. Usia menarche seorang anak perempuan, ratarata usia untuk mencapai menarche adalah 12 - 13 tahun. Tetapi menarche ada yang dicapai pada usia18 tahun. Beberapa ahli yang melakukan penelitian menyimpulkan semakin muda seorang mengalami menstruasi pertama kalinya, semakin tua atau lama ia memasuki masa menopause (Proverawati dan Misaroh, 2010; Kumalasari dan Andhyantoro, 2012)

Selain usia menarce menopause di pengarui juga oleh jumlah anak yg dilahirkan dari seorang ibu. Menurut beberapa penelitian mengatakan bahwa jumlah anak berpengaruh secara signifikan mempengaruhi seorang ibu memasuki masa menopause seperti penelitian yang dilakukan oleh Fallahzadeh (2010) terdapat hubungan signifikan antara jumlah anak dengan kualitas hidup pada wanita menopause.

Di Indonesia, pada tahun 2025 diperkirakan akan ada 60 juta perempuan menopause. Pada tahun 2017 di Indonesia tercatat sebesar 23,4 juta usia lanjut $8,97 \%$ dan 7,4 \% dari total penduduk adalah usia menopause (BPS, 2017). Sementara perkiraan umur rata-rata usia menopause di Indonesia adalah 50 tahun. Peningkatan usia harapan hidup menyebabkan jumlah perempuan yang mengalami menopause semakin banyak (Dep Kes RI, 2016). Menurut Badan Pusat Statistik pada tahun 2016, jumlah penduduk wanita di Jawa Tengah adalah 944.320 jiwa dengan jumlah penduduk wanita pada kelompok umur 50-54 tahun dan diperkirakan telah memasuki usia menopause sebanyak 916.446 jiwa. Sedangkan tahun 2015 ada sebanyak 6.318 .990 jiwa dengan jumlah penduduk wanita yang berusia 50-54 tahun ada 1.041.614 jiwa. Jumlah penduduk wanita di kota Kartasura pada tahun 2014ada sebanyak 1.039.681 jiwa dengan jumlah wanita yang berusia 50-54 tahun ada 138.813 jiwa (BPS: 2017 ). Di Kota Boyolali menurut data dari Badan Keluarga Berencana Daerah Kabupaten Boyolali, jumlah penduduk perempuan yang sudah menopause pada tahun 2017 tercatat 34.092 jiwa dari 974.579 jiwa jumlah seluruh penduduk perempuan atau $(2,86 \%)$ dari jumlah seluruh penduduk perempuan.

Studi pendahuluan dilakukan sebelum melakukan penelitian didapatkan data jumlah penduduk wanita sebanyak 2.746 orang. Jumlah penduduk wanita yang sudah menopause sebanyak 451 atau $(13,38 \%)$ dari jumlah seluruh penduduk wanita dan dari wawancara $20 \mathrm{ibu}$ menopause rata-rata mendapatkan menarche ketika usia 13 tahun yaitu sebanyak 30\%, menopause di umur 49-50 tahun sebanyak $80 \%$. Tujuan dari penelitian ini adalah untuk mengetahui apakah usia menarche dan jumlah anak berhubungan dengan usia menopause di Kelurahan Karangjati, Wonosegoro, Boyolali.

\section{METODE}

Metode yang digunakan dalam penelitian ini adalah observasional analitik yang bertujuan untuk mengungkapkan hubungan korelatif antar variabel, dengan pendekatan retrospektif. Populasi yang digunakan dalam penelitian ini adalah ibu-ibu yang sudah mengalami masa menopause di Kelurahan Karangjati, Wonosegoro, Boyolali.. Jumlah sampel sebanyak 82 ibu menopause yang 
memenuhi kriteria inklusi dan eksklusi. Teknik pengambilan sampel menggunakan simple random sampling.

Instrumen penelitian yamg digunakan dalam penelitian ini berupa lembar observasi. Data yang digunakan dalam penelitian ini terdiri atas satu jenis yaitu: data primer diperoleh langsung dari wawancara responden dan lembar observasi. Analisis Data menggunakan menggunakan korelasi pearson. Kriteria pengujian yaitu : $\mathrm{H}_{\mathrm{o}}$ diterima bila $p$ value $\geq 0,05$.

\section{HASIL DAN PEMBAHASAN}

Penelitian bertujuan untuk mengetahui ada tidaknya hubungan antara jumlah anak dan usia menarche dengan usia menopause pada ibu menopause di Kelurahan Karangjati, Kecamatan Wonosegoro, dengan hasil sebagai berikut:

1. Karakteristik Responden

a. Usia

Hasil penelitian karakteristik responden berdasarkan usia pada ibu menopause di Kelurahan Karangjati, Kecamatan Wonosegoro, dapat dilihat pada tabel berikut ini:

Tabel 1. Distribusi frekwensi Karakteristik Responden berdasarkan Umur

\begin{tabular}{ccc}
\hline Umur & Frekuensi (n) & Presentase (\%) \\
\hline $46-50$ & 36 & $43,9 \%$ \\
$51-55$ & 40 & $48,8 \%$ \\
$56-60$ & 6 & $7.3 \%$ \\
\hline Jumlah & 82 & $100 \%$ \\
\hline
\end{tabular}

Sumber data primer

Hasil penelitian pada Tabel 1. menunjukkan pembagian kelompok usia pada ibu menopause di Kelurahan Karangjati, Kecamatan Wonosegoro. Hasil penelitian menunjukkan sebagian besar ibu dengan usia 51-55 tahun yaitu sebanyak 40 responden $(48,8 \%)$. Pada umumnya usia menopause terjadi pada usia 50-an tahun. Hasil penelitian ini didukung oleh pendapat Kusmiran (2011) yang menyatakan rata-rata menopause natural terjadi pada usia 51,4 tahun untuk negara industri, dan secara umum terjadi ketika wanita memasuki usia 40 hingga 58 tahun. Apabila diambil rata-rata, seorang wanita akan mengalami menopause sekitar usia 45-50 tahun.

b. Pekerjaan

Hasil penelitian karakteristik responden berdasarkan pekerjaan pada ibu menopause di Kelurahan Karangjati, Wonosegoro, dapat dilihat pada Tabel berikut ini, dapat dilihat pada Gambar berikut ini:

Tabel 2. Distribusi frekwensi Karakteristik Responden berdasarkan Pekerjaan

\begin{tabular}{ccc}
\hline Pekerjaan & Frekwensi (n) & Presentase (\%) \\
\hline Bekerja & 54 & $65.9 \%$ \\
Tidak bekerja & 28 & $34,1 \%$
\end{tabular}


$\frac{\text { Jumlah }}{\text { Sumber data primer }}$

82

$100 \%$

Tabel 2. distribusi pekerjaan pada ibu menopause di Kelurahan Karangjati, Wonosegoro. Pada tabel tersebut menunjukkan ibu yang bekerja sebanyak 54 responden $(65,9 \%)$ dan ibu yang tidak bekerja sebanyak 28 responden $(34,1 \%)$. Pekerjaan mempengaruhi aktivitas fisik dan psikologi pada waktu bekerja. Kasdu (2012) menjelaskan status pekerjaan mempengaruhi kondisi psikis wanita. Wanita yang bekerja akan mengalami usia menopause lebih lama dibandingkan dengan wanita yang tidak bekerja atau tidak menikah. Pekerjaan tidak mempengaruhi usia menopause secara langsung. Hal ini diperkuat oleh penelitian Safitri (2014) pekerjaan tidak berpengaruh signifikan terhadap usia menopause. Pekerjaan hanya memperlambat usia menopause, tergantung kondisi psikis serta berat ringannya pekerjaan.

c. Usia Menarche

Hasil penelitian karakteristik responden berdasarkan usia menarche pada ibu menopause di Kelurahan Karangjati, Kecamatan Wonosegoro, dapat dilihat pada Tabel berikut ini:

Tabel 3. Distribusi Frekwensi Karakteristik Responden berdasarkan Usia

\begin{tabular}{ccc}
\multicolumn{3}{c}{ Menarche } \\
\hline Usia (th) & Frekwensi (n) & Presentase (\%) \\
\hline 10 & 5 & $6,1 \%$ \\
11 & 4 & $4,9 \%$ \\
12 & 19 & $23,2 \%$ \\
13 & 23 & $28,0 \%$ \\
14 & 28 & $34,1 \%$ \\
15 & 3 & $3,7 \%$ \\
\hline Jumlah & 82 & $100 \%$
\end{tabular}

Sumber data primer

Tabel 3. menunjukkan pembagian kelompok usia menarche pada ibu menopause di Kelurahan Karangjati, Kecamatan Wonosegoro. Hasil penelitian sebagian besar ibu dengan usia menarche 14 tahun yaitu sebanyak 28 responden $(34,1 \%)$ dan sebagian kecil dengan usia menarche 15 tahun yaitu sebanyak 3 responden $(3,7 \%)$. Hasil penelitian sesuai dengan pendapat dari Proverawati dan Misaroh (2010) terdapat kecenderungan bahwa saat ini anak mendapat menstruasi yang pertama kali pada usia yang lebih muda. Ada yang berusia 12 tahun saat ia mendapat menstruasi pertama kali, tapi ada juga yang 8 tahun sudah memulai siklusnya.

Hasil penelitian Kusnita dan Damarati (2012) usia menache pada umumnya terjadi di usia 9-12 tahun. Sedangkan penelitian Asmika, et al (2016) menjelaskan di Indonesia usia menarche turun dengan rata- rata usia menarche 0,145 tahun per dekade.

d. Jumlah Anak 
Hasil penelitian karakteristik responden berdasarkan jumlah anak pada ibu menopause di Kelurahan Karangjati, Kecamatan Wonosegoro, dapat dilihat pada tabel berikut ini:

Tabel 4. Distribusi Frekwensi Karakteristik Responden berdasarkan Jumlah

\begin{tabular}{ccc} 
& Anak & \\
\hline Jumlah anak & Frekwensi (n) & Presentase (\%) \\
\hline 1 & 1 & $1,2 \%$ \\
2 & 15 & $18,3 \%$ \\
3 & 16 & $19,5 \%$ \\
4 & 25 & $30,4 \%$ \\
5 & 13 & $15,9 \%$ \\
6 & 12 & $14,7 \%$ \\
\hline Jumlah & 82 & $100 \%$
\end{tabular}

Tabel 4. menunjukkan jumlah anak pada ibu menopause di Karangjati, Wonosegoro. Hasil penelitian sebagian besar ibu dengan jumlah anak 4 anak yaitu sebanyak 25 responden (30,4\%). Jumlah anak atau usia terakhir melahirkan dapat mempengaruhi umur menopause. Makin sering melahirkan, makin tua baru memasuki usia menopause. Semakin tua seseorang melahirkan anak, semakin tua ia mulai memasuki usia menopause. Kasdu (2012) menjelaskan semakin sering ibu melahirkan anak usia menopausenya semakin lama. Hasil penelitian ini didukung oleh penelitian Safitri (2014) ada hubungan signifikan antara Jumlah anak dan usia terakhir melahirkan terhadap usia menopause.

e. Usia Menopause

Hasil penelitian karakteristik responden berdasarkan usia menopause pada ibu menopause di Kelurahan Karangjati, Kecamatan Wonosegoro, dapat dilihat pada Tabel berikut ini:

Tabel 5. Distribusi Frekwensi Karakteristik Responden berdasarkan Usia Menopause

\begin{tabular}{ccl}
\hline Usia menopause & Frekwensi (n) & Presentase (\%) \\
\hline 45 & 4 & $4,9 \%$ \\
46 & 2 & $2.4 \%$ \\
47 & 5 & $6,1 \%$ \\
48 & 19 & $23,2 \%$ \\
49 & 5 & $6,1 \%$ \\
50 & 30 & $36,6 \%$ \\
52 & 7 & $8,5 \%$ \\
53 & 4 & $4,9 \%$ \\
55 & 6 & $7,3 \%$ \\
Jumlah & 82 & $100 \%$ \\
\hline
\end{tabular}

Sumber data primer

Tabel 5. menunjukkan pembagian kelompok usia menopause pada ibu menopause di Kelurahan Karangjati, Kecamatan Wonosegoro. Hasil penelitian sebagian besar ibu dengan usia menopause 50 tahun yaitu 
sebanyak 30 responden (36,6\%). Menopause adalah masa berakhirnya siklus menstruasi yang terdiagnosis setelah 12 bulan tanpa periode menstruasi. Menurut Kusmiran (2011) tata-rata menopause natural terjadi pada usia 51,4 tahun untuk negara industri, secara umum terjadi pada usia 40-58 tahun. Sedangkan menurut Proverawati (2010) jika diambil rata-rata, seorang wanita akan mengalami menopause sekitar usia 45-50 tahun. Hasil penelitian menunjukkan rentang usia menopause 4555 tahun, hasil ini sesuai dengan teori atau umumnya usia menopause.

Hasil penelitian sejalan dengan penelitian Nani (2016) yang mengadakan penelitian usia menopause pada wanita yang menggunakan kontrasepsi hormonal, usia menopause dengan rentang dari 40-59 tahun. Menurut Larasati (2012) wanita pada usia 40 sampai 50 tahun mengalami masa peralihan dari siklus haid yang rutin setiap bulan ke masa menopause dimana, terjadi perubahaan- perubahaan fisik dan juga kejiwaan pada diri seorang wanita. Pada masa menjelang menopause, estrogen yang dihasilkan semakin turun sampai masa menopause tiba. Sulit memang untuk menentukan batasan dan mengelompokkan gejala serta tanda-tanda menopause secara medis dengan tepat. Misalnya, mengartikan menopause dengan berhentinya haid, padahal menopause bukan hanya ditandai oleh berhentinya haid, tetapi beberapa tahun sebelumnya sudah ditandai oleh keluhan-keluhan fisik maupun psikis.

2. Analisis Hubungan Usia Menarche dan Jumlah Anak dengan Usia Menopause.

Hubungan antara usia menarche dengan usia menopause pada ibu menopause di Kelurahan Karangjati, Kecamatan Wonosegoro diukur dengan menggunakan korelasi Pearson Product Moment. Hasil uji korelasi Pearson dapat dilihat pada tabel berikut ini.

Tabel 6. Hasil Uji Korelasi Pearson

\begin{tabular}{cccc}
\hline Variabel & Nilai Rata-rata & $\mathbf{r}$ & $\mathbf{p}$ \\
\hline Usia menarche & 12,90 & $-0,580$ & $<0,001$ \\
Jumlah Anak & 3,90 & 0,148 & 0,185 \\
Usia menopause & 49,63 & & \\
\hline
\end{tabular}

Pada tabel 6. di atas menunjukkan nilai rata-rata pada variabel usia menarche sebesar 13, sedangkan nilai rata-rata pada variabel usia menopause sebesar 49. Nilai koefisien korelasi menarche dan usia menopause sebesar (-) 0,580 dengan parameter negatif, sehingga dapat disimpulkan bahwa semakin muda usia menarche maka semakin tua usia menopausenya. Hasil uji statistik menunjukkan $\mathrm{p}$ value $(<0,001)<0,05$ disimpulkan Ho ditolak dan $\mathrm{Ha}$ diterima hal ini berarti ada hubungan signifikan agak rendah berdasarkan tabel koefesien antara usia menarche dengan usia menopause di Kelurahan Karangjati, Wonosegoro, Boyolali.

Usia menarche merupakan usia saat pertama kali mengalami menstruasi. Menarche merupakan pertanda awal mulanya fungsi ovarium untuk berovulasi dan menandakan terjadinya pubertas pada seorang wanita. Usia terjadinya menarche seringkali dihubungkan dengan masalah kesehatan terutama kesehatan reproduksi. 
Beberapa penelitian seringkali menyatakan bahwa terdapat hubungan antara usia menarche dengan usia terjadinya menopause (Qiu, C dkk, 2012)

Penelitian di Polandia menyatakan bahwa wanita dengan usia menarche yang lebih awal akan mengalami menopause 0,3 tahun lebih cepat dibandingkan dengan wanita dengan usia menarche yang lebih lama (Kaczmarek, 2017). Penelitian di wilayah rural Turki menyatakan bahwa usia menarche kurang dari 13 tahun mencegah terjadinya menopause dini (Vehid dkk, 2016). Wanita yang mengalami menarche pada usia yang lebih cepat memiliki jumlah Anti-Mullerian hormone $(\mathrm{AMH})$ yang lebih tinggi dibandingkan dengan wanita yang mengalami menarche pada usia yang lebih lambat.

Menurut Speroff dan Reitz (2010), wanita yang terlambat mendapatkan menstruasi, pada usia 16 atau 17 tahun, mengalami menopause lebih dini, sedangkan mereka yang haid lebih dini rata-rata mengalami menopause pada usia mencapai 50 tahun. Ada pola keluarga yang berlaku secara umum, bagi seorang wanita yang ibu atau kakak perempuannya lebih dini mengalami menopause maka ia juga cenderung mengalami hal yang sama, begitu pula sebaliknya.

Hasil penelitian ini sejalan dengan penelitian yang dilakukan oleh Anggraini (2015) menopause diduga ada hubungannya dengan menarche. Makin dini menarche terjadi, makin lambat menopause timbul. Sebaliknya, makin lambat menarche terjadi makin cepat menopause timbul. Pada abad ini umumnya nampak bahwa menarche makin dini timbul dan menopause makin lambat terjadi, sehingga masa reproduksinya menjadi lebih panjang. Dalton yang dikutip dari Safitri (2014) menjelaskan wanita yang terlambat mendapatkan menstruasi pada usia 16 atau 17 tahun, justru akan mengalami menopause lebih dini, sedangkan mereka yang mengalami haid dini akan mengalami usia menopause mencapai 50 tahun. Faktor keturunan berperan dalam usia menarche dan usia menopause, bagi seorang wanita yang ibu atau kaka perempuannya lebih dini mengalami menopause maka ia cenderung mengalami hal yang sama, begitu pula sebaliknya.

Nilai rata-rata pada variabel jumlah anak sebesar 3,90 dan nilai rata-rata pada variabel usia menopause sebesar 49,63. Nilai koefisien korelasi sebesar 0,148. Hasil uji angka signifikan 0,185 > 0,05 disimpulkan Ho diterima dan Ha ditolak hal ini berarti tidak ada hubungan jumlah anak yang dilahirkan dengan usia menopause pada ibu menopause di Kelurahan Karangjati, Wonosegoro.

Hasil penelitian ini tidak mendukung dari penelitiannya Kasdu (2012) dan Safitri (2014) bahwa semakin sering ibu melahirkan anak usia menopausenya semakin lama dan ada hubungan signifikan antara Jumlah anak dan usia terakhir melahirkan dengan usia menopause.

Jumlah anak berhubungan dengan paritas dimana jumlah anak yang banyak bearti paritas ibu tinggi. Penelitian Pathak (2010) menyatakan bahwa wanita dengan punya anak sedikit cenderung akan mengalami menopause pada usia dini dibandingkan dengan wanita dengan jumlah paritas yang lebih banyak. Hal tersebut didukung oleh penelitian Delavar (2011) bahwa wanita yang tidak memiliki anak akan mengalami menopause lebih awal. Penelitian lain menyatakan hal yang sama bahwa semakin banyak wanita mempunyai banyak anak akan semakin lama wanita tersebut mengalami menopause. Hal ini mungkin disebabkan oleh jumlah cadangan ovarium atau tingkat Anti- Mullerian Hormone pada saat dewasa tinggi. Namun, hasil penelitian Bragg, yang dilakukan pada wanita sejak lahir hingga dewasa muda, menyatakan bahwa pada wanita dengan paritas lebih banyak yang lebih 
tinggi memiliki kadar Anti- Mullerian Hormone yang sedikit dibandingkan dengan paritas rendah (Bragg. dkk, 2012).

Wanita dengan julah anak banyak atau paritas tinggi, memiliki jumlah kumulatif siklus menstruasi yang lebih rendah dibandingkan dengan wanita yang tidak memiliki anak, dengan demikian dapat mempengaruhi jumlah cadangan oosit yang lebih banyak dan paparan hormon estrogen yang lebih lama sehingga wanita yang memiliki anak banyak bearti paritasnya tinggi cenderung akan mengalami menopause pada usia yang lebih lambat (Dorjgochoo, 2012; Wahyu, 2015).

Beberapa penelitian diatas berasumsi bahwa ada hubungan antar jumlah anak yang dilahirkan berhubungan dengan usia menopause, tetapi hasil dari penelitian disini ternyata tidak berhubungan secara signifikan antara jumlah anak dengan usia menopause dapat dikatakan bahwa hasil penelitian tidak mendukung dengan hasil penelitian para peneliti terdahulu, sehingga perlu diadakan penelitian lagi yang menguji ada tidaknya kemungkinan atau beberapa faktor-faktor lain yang hubungan dengan usia menopause.

\section{SIMPULAN}

Berdasarkan hasil penelitian tentang hubungan usia menarche dan jumlah anak dengan usia menopause di Kelurahan Karangjati, Wonosegoro, Boyolali dapat diambil kesimpulan sebagai berikut: Usia menarche ibu sebagian besar dengan usia 14 tahun, usia menopause ibu sebagian besar dengan usia menopause 50 tahun, ada hubungan signifikan antara usia menarche dengan usia menopause pada ibu menopause, Tidak ada hubungan secara signifikan antara jumlah anak dengan usia menopause pada ibu menopause di Kelurahan Karangjati, Wonosegoro, Boyolali.

\section{SARAN}

Dari kesimpulan diatas maka penulis menyarankan agar para Bidan dapat menjelaskan atau memberi informasi tidak hanya usia menarche dan usia menopause, tetapi faktor lain yang juga mempengaruhi usia menopause seseorang serta persiapan apa yang harus dilakukan oleh seorang ibu, sehingga ibu yang akan memasuki masa menopause lebih siap menghadapinya.

Perangkat desa dapat mendukung kebijakan-kebijakan kesehatan yang berkaitan dengan penanganan wanita usia menopause dengan cara mengaktifkan kegiatan-kegiatan di Posyandu Lansia serta mendorong partisipasi dari kader kesehatan atau petugas kesehatan yang berada di wilayahnya.

\section{DAFTAR PUSTAKA}

Anggraini. M. T. 2015. Hubungan antara Usia Saat Timbulnya Menarche dengan Usia Saat Terjadinya Menopause Wanita Di Kecamatan Kartasura. Jurnal FK Unimus

Asmika, Ruhana A, dan Rusdyanti. 2016. Hubungan Aktivitas Fisik dan Persentase Lemak Tubuh dengan Usia Menarche Pada Siswi SMPN 3 Candi Sidoarjo. Naskah Publikasi Program Studi Pendidikan Dokter FKUB 
BPS. 2017. https://www.bps.go.id/subject/12/kependudukan.html. Diakses 30 Februari 2018

Bragg, Jared M, dkk. 2012. Age at Menarche and Parity are Independently Associated with Anti-Mu" llerian Hormone, a Marker of Ovarian Reserve, in Filipino Young Adult Women. American Journal Of Human Biology 00:000-000

Delavar MA and M Hajiahmadi. 2011. Factors Affecting the Age in Normal Menopause and frequency of Menopausal Symptoms in Northern Iran. Iranian Red Crescent Medical Journal 13(3).

Departemen Kesehatan RI. 2016. Terjadi pergeseran usia menopause. http://www.depkes.go.id/index.php?option=articles\&task=viewarticle \& artid=280. Diakses 30 Oktober 2017

Dorjgochoo, Tsogzolmaa, dkk. 2012. Dietary and lifestyle predictors of age at natural menopause and reproductive span in the Shanghai Women's Health Study. Menopause. 15(5).

Fallahzadeh, H. 2010. Quality of Life After the Menopause in Iran: A Population Study. Qual Life Res. 19 (6)

Kaczmarek, Maria. 2017. The timing of natural menopause in Poland and associated factors. Maturitas 57.

Kasdu. 2012. Kiat Sehat dan Bahagia di Usia Menopause. Jakarta: Pustaka Pembangunan Swadaya Nusantara

Kumalasari dan Andhyantoro. 2012. Kesehatan Reproduksi Untuk Mahasiswa Kebidanan dan Keperawatan. Jakarta: Salemba medika.

Kusmiran, E. 2011. Kesehatan Reproduksi Remaja Dan Wanita. Jakarta: Salemba Medika.

Kusnita dan Damarati. 2012. Pengaruh Status Gizi Remaja Terhadap Usia Menarche Pada Siswi SDN Dukuh Menanggal Surabaya. Jurnal Universitas PGRI Adi Buana Surabaya

Larasati. 2012. Jurnal Kualitas Hidup Pada Wanita Yang Sudah Memasuki Masa Menopause. Jakarta: Fakultas Psikologi Universitas Gunadarma

Lestary, Dwi. 2010. Seluk Beluk Menopause. Jakarta: Gerailmu.

Nani. D. 2016. Hubungan Umur Awal Menopause dan Status Penggunaan Kontrasepsi Hormonal Dengan Kejadian Kanker Payudara. Jurnal Keperawatan Soedirman (The Sudirman Journal of Nursing), Volume 14, No.3, November 2016

Pathak, R.K and Purnima Parashar. 2010. Age at Menopause and Associated Bio- Social Factors of Health in Punjabi Women. The Open Anthropology Journal, 13 (3).

Proverawati, Misaroh. 2010. Menarche Menstruasi Pertama Penuh Makna. Yogyakarta: Nuha Medika. 
Qiu, C, dkk. 2012. Associations Between age At Menarche and Menopause with Cardiovascular Disease, Diabetes, and Osteoporosis in Chinese Woman. Pubmed. 1

Safitri, A. 2014. Beberapa Faktor Yang Mempengaruhi Menopause Pada Wanita Di Kelurahan Titi Papan, Kota Medan Tahun 2014. USU Repository

Speroff, L \& Reitz, M. 2010. Clinical Gynecologic Endocrinology and Infertility. Lippincott Williams \& Wilkins. USA

Vehid, Suphi, dkk.2016. The prevalence and the age at the onset of menopause in Turkish women in rural area. Saudi Med J 2016; Vol. 27.

Wahyu, O. 2015. Hubungan Usia Melahirkan Terakhir dengan Usia Menopause di Desa Porong Kecamatan Porong Kabupaten Sidoarjo. UNESA Repository. 